THE GROSS AND MICROANATOMY OF THE DIGESTIVE TRACT AND PANCREAS OF THE CHANNEL CATFISH, ICTALURUS PUNCTATUS

by

RONALD LESTER GAMMON

B. S., Kansas State University, 1968

B. S., Kansas State University, 1970

A MASTER'S THESIS

submitted in partial fulfillment of the

requirements for the degree

MASTER OF SCIENCE

Division of Biology

KANSAS STATE UNIVERSITY

Manhattan, Kansas

1970

Approved by:

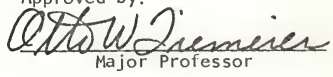




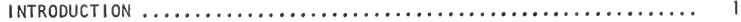

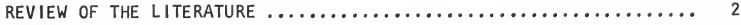

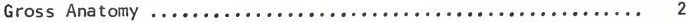

Mouth $\ldots \ldots \ldots \ldots \ldots \ldots \ldots \ldots \ldots \ldots \ldots \ldots \ldots \ldots \ldots \ldots, 2$

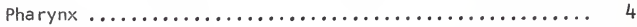

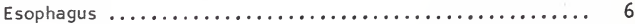

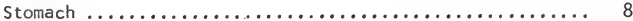

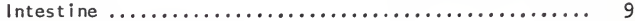

Histological Characteristics .................... 11

Buccal Cavity ............................ 11

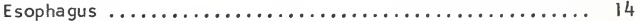

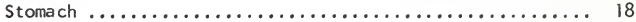

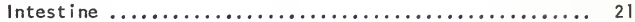

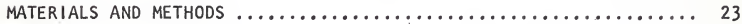

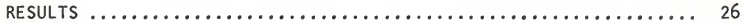

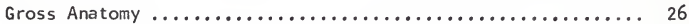

Oral Cavity and Pharynx ....................... 26

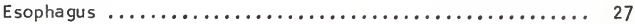

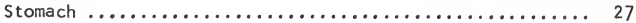

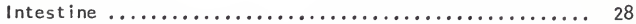

Histological Characteristics .................... 28

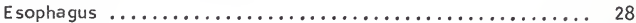

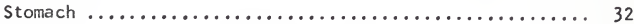


Intestine $\ldots \ldots \ldots \ldots \ldots \ldots \ldots \ldots \ldots \ldots \ldots \ldots \ldots \ldots \ldots \ldots \ldots \ldots, 36$

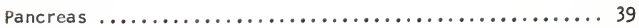

DISCUSSION ........................................... 41

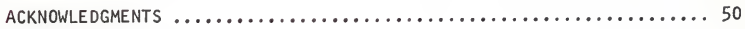

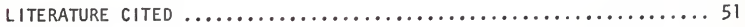




\section{INTRODUCTION}

During recent years lctalurus punctatus, the channel catfish, has become an economically important species for food and for sport.

Sport fishermen have increasingly sought the channel catfish because these fish grow large enough to be fun for the sportsman to catch and the fish caught have good flavor. Consequently, many federal, state, and private lakes are stocked regularly.

The use of channel catfish as a source of protein for human consumption has made the rearing of channel catfish an important industry. Since this fish is easy to raise and feed, its importance as a human foodstuff seems likely to increase in the future. Millions of pounds of fish are harvested each year from commercial establishments.

The increased economic importance of the fish has stimulated much interest during recent years. Extensive studies have been undertaken to determine the feeding habits of the channel catfish and nutritional requirements. Feeds to increase weight gains per pound of feed consumed have been formulated and tested.

This study was undertaken to determine the structure of the tissue and changes in the digestive tract during the season when catfish are actively feeding compared to that in the colder months when less food is ingested. It was postulated that if there were changes in the microanatomy there might also be changes in the enzymes present which would affect digestion. Therefore, this study 
may be the basis for an analysis of the enzymatic constituents at high and low temperatures. Hopefully the industries associated with channel catfish will benefit by the increased knowledge of the channel catfish.

\author{
REVIEW OF THE LITERATURE
}

\title{
Gross Anatomy
}

Mouth

The digestive tract of $f$ ishes can be divided into mouth, esophagus, stomach, and intestine. Specialization of each division has occurred. The mouth of any fish is highly adapted for its feeding habits, and ranges from the sharp features of carnivores to the thick, fleshy lips of bottom-feeders.

Weisel (1962) in a comparative study of the digestive tract of a longnose sucker (Catostomus catostomus), and the squawfish, a predaceous minnow (Ptychoeheilas oregonense), described the mouth of the minnow as "large, terminal and having no associated barbels or fleshy lips", while the mouth of the longnose sucker was "small protractile, ventral and provided with fleshy, sensory lips". The buccal cavity of the Indian gudgeon (Glossogobius giurus (Ham)) is quite long and wide and has a wide cleft; the lips are not thick (Mohsin, 1961). Blake (1930) related the histology of the sea bass (Centropriestes striatus), also a predaceous fish, but did not include the mouth or 
pharyngeal cavities in his description. Sehgal (1966) reported the mouth of Labeo calbasu (Hamilton), a herbivorous fish, as inferior in position and bounded by soft, fleshy and fringed lips which aid in grasping of food and the buccal cavity as a small chamber leading into the pharynx. According to Girgis (1952) the mouth of Labeo horie (Cuvier) is inferior and extremely protractile and the mucosa of the roof of the buccal cavity is thrown into slight transverse foldings. He described a "lamellar organ of the palate" extending almost to the posterior end of the roof. The floor of the buccal cavity contains shallow foldings which are prominent posteriorly and no true tongue is present. The mouth of Mulloides auriflamma, a bottom-feeder, is highly protrusible, directed downwards, and possesses "obsolete" lips, microscopic villiform teeth, and a rudimentary tongue (Al-Hussaini, 1946). On the roof of the mouth and on the tongue are are longitudinal rows of papillary structures which resemble the "gustatory papillae" of mammals. Atherina forskali (Rüpp), a planktonfeeder (Al-Hussaini, 1947) possesses a moderately protrusible mouth not guarded by lips, weak dentition, a spatulate tongue with minute papillae, free anteriorly, and longitudinal folds on the roof of the buccal cavity, but not on the floor. The buccal cavity of the carp (Carpio communis (Curry, 1939)) is bounded by protrusible lips anteriorly, and contains a rudimentary tongue. Ridges of knob-like papillae are found in the mucosa of the roof. The mouth and buccal cavity of the cod (Gadus morhua) has numerous conical teeth, longitudinal mucosal folds on the roof, and a rudimentary tongue (Bishop and Odense, 1966). The division 
between buccal and pharyngeal cavity was defined as being at the first gill cleft. They also identified "two dorsal convex cartilaginous plates which fit into two smaller ventral concave plates". Each tooth has several muscle attachments and is covered with conical teeth. Al though McVay and Kaan (1940) studied the digestive system of the goldfish (Carassius auratus) their description began with the posterior pharynx. Blake (1936) did not include the buccal or pharyngeal cavities in his study of the sea robin (Prionotus carolinus), a bottom-feeder, or the sea bass, a predaceous fish.

\section{Pharynx}

The pharyngeal arches of the longnose sucker (Weisel, 1962) are. well adapted for filtering food. The roof of the pharynx.contains a pharyngeal pad. The gill rakers are well-developed and, because they interdigitate when the pharynx is constricted, they can act as a strainer. The gill rakers of the squawfish on the other hand are "bluntly pointed and are not papillose" and interdigitate but not to the extent found in the sucker. Pharyngeal teeth are found in the fifth arch of both species. These teeth, according to Weisel (1962) serve as strainers in the longnose sucker but "serve for holding and working large food items through the esophagus" in the squawfish. The pharyngeal pad of the longnose sucker is not cornified, has fine folds and papillae which bear taste buds, and is covered with numerous mucous cells. This pad is "large and extends to the anterior part of the pharynx to function in feeding". By comparison, 
the pharyngeal pad of the squawfish is smaller and located at the posterior part of the pharynx. The epithelium is cornified but has no taste buds, ridges or papillae. The mucous cells occur only at the margins of the pad where cornification is reduced. The pharynx of the Indian gudgeon is siall with minute pharyngeal teeth arranged in two small pads (Mohsin, 1961). Girgus (1952) divided the pharynx into an "anterior gustatory and respiratory part followed by a posterior masticatory one". The roof of the anterior pharynx is formed of a pharyngeal pad which Valatour (1861) referred to as the "palatal organ" (Girgis, 1952). Because valatour considered this pad to be a tongue, it thus became known as the "palatal organ of Valatour" or "Valatour's tongue". Previous to Valatour, this organ was considered as a gland by Cuvier and Duvernoy (Curry, 1939). The surface of this pad contains "papillae which are long and scattered anteriorly, but become short and densely crowded posteriorly' (Girgis, 1952). The horny pad forms the roof of the posterior pharynx, while the floor of the anterior pharynx is slightly convex and contains a few conical papillae. The surface of the floor of the posterior part is slightly concave with two sets of pharyngeal teeth. Labeo calbasu (Sehgal, 1966) has a cornified horny pad on the roof of the pharynx and pharyngeal teeth on the fifth branchial arch forming an efficient masticatory apparatus. From Al-Hussaini's (1946) study, the bottom-feeder (Mulloides auriflamma) has cushions containing granular teeth on the floor of the pharynx that "make a kind of mill mechanism for mincing food". The gill rakers of Mulloides auriflamma were not as well developed as those of the plankton-feeder, Atherina forskali (Al-Hussaini, 
1946, 1947). By comparison Al-Hussaini (1946) reported the pharyngobranchials of the third and fourth arches fused to form two convex cushions studded with villiform teeth. On the floor of the pharynx, the pharyngeals are completely coalesced to form a triangular plate, flat in the middle and concave on the sides.

\section{Esophagus}

The esophagus of most $\mathrm{fish}$ is no more than a passage from the pharynx to the stomach or anterior end of the intestine. Weisel (1962) stated: "The esophagus is the short constriction between the pharynx and the intestine", thus the squawfish and the longnose sucker lacked a stomach. In the Indian gudgeon, the esophagus was "very small and tubular" (Mohsin, 1961). In the sea robin (Blake, 1936) the esophageal boundary was "well defined microscopically at the pharyngeal boundary whereas at the gastric limit it is difficult to determine'. The sea robin (Blake, 1930) has a "rather short and muscular esophagus" with the anterior and posterior boundaries indefinite, and differentiation between parts being most difficult at the gastric limit. He further stated that "longitudinal folds, with grooves of varying depth and width between them; are continuous with similar structures in the stomach as well as in the buccal cavity'". The esophagus of Labeo horie is "a small muscular tube that serves to connect the pharynx with the intestinal bulb"' (Sehgal, 1965). The esophagus of $\underline{L}$. horie runs from the posterior end of the pharynx, in a postero-ventral 
direction, to the anterior end of the intestinal swelling (Girgis, 1952). This esophagus "lies partly within and partly anterior to the body cavity" and the transition into the intestinal swelling is "marked externally by a slight constriction followed by an appreciable increase in diameter'". Al-Hussaini (1947) reported the esophagus of Atherina forskali, a plankton-feeder, "gradually merging from the pharynx and extending backwards dorsally to the heart to pierce the transverse septum" then "passing insensibly into the intestine". While the esophagus of the bottom-feeder Mulloides auriflamma (Al-Hussaini, 1946) is "short and stout" the "line of demarkation between esophagus and stomach can be easily recognized internally by more numerous mucosal folds in the esophagus than in the neighboring cardiac region, where the folds are fewer and thicker". The esophagus of the carp (curry, 1939) is "a short muscular tube connecting the pharynx with the large arm of the intestine", where "the inner surface is covered by the twelve deep longitudinal folds which become continuous with those of the intestine". The esophagus of the cod is "not well differentiated externally from the curved stomach" (Bishop and Odense, 1966). According to McVay and Kaan (1940) the goldfish lacks a stomach. The esophageal boundaries were clearly marked by a circular constriction but internally, "a difference was evident both in relative size and in the complexity of the mucosal folds". Their description does not include the characteristics of the esophageal junction which grossly mark this boundary. 
Stomach

A stomach is not present in all fishes but when present is generally syphon-shaped. There is no stomach in either the longnose sucker or the squawfish (Weisel, 1962). "The anterior limb of the intestine of the squawfish is enlarged and undoubtedly capable of enough distension to receive large items of food"; while in the sucker the intestine "is hardly larger in circumference than in the rest of the tract". Mohsin (1961) reported a "well-developed stomach in Glossogobius giuris". The pylorus of this fish is "not distinct but can be located upon dissection by the presence of a sphincter". The sea bass has a caecal type stomach (Blake, 1930) which has cardiac and pyloric regions. The pyloric region can be differentiated from the intestine by the pyloric valve, and by the fact that "the longitudinal folds of the cardiac region are deeper than any region of the enteron". In the sea bass, short, irregular folds form a ridge which is thrown up to form "a sort of barrier" between the cardiac and pyloric regions. The folds of the pyloric region are more shallow and shorter than those of the cardiac. The stomach of the sea robin (Blake, 1936) is of the caecal regions and the pyloric portion consists of a ventral diverticulum. In a comparison of the mucosal folds, Blake (1936) reported the gastric mucosa was ridged longitudinally in the sea bass, and had both primary and secondary folds which were neither "so regular nor so continuous" in the sea robin, "although fully as deep". The shape of the stomach of both the sea bass and the sea robin was dependent upon its content. 
Labeo calbasu (Sehgal, 1966) has no true stomach but the "posterior end of the esophagus is enlarged into a long, bag-like structure called the intestinal bulb. An intestinal swelling in Labeo rohita was described by Girgis (1952). Al-Hussaini (1947) cited several authors and made notes of two terms; intestinal swelling and intestinal bulb which are distinguished by external appearance. The plankton-feeder, Atherina forskali, (Al-Hussaini, 1946) has an intestinal bulb in which "the individuality of the mucosal folds becomes lost and instead the mucosal lining becomes reticular and extends as such throughout the intestine proper". The bottom-feeder, Mulloides auriflamma, (Al-Hussaini, 1946) has a caecal type stomach with the mucosa of the pyloric region "lifted into four mucosal belts... (and) one of the belts is functional in forming the pyloric orifice". Curry (1939) reported that the carp lacks a stomach and the "esophagus on entering the peritoneal cavity enlarges suddenly to form the intestine". In the cod (Bishop and Odense, 1966), "the stomach is intermediate between the siphonal and caecal types described by Grasse (1958)". In this stomach there is a pouch between the cardiac and pyloric portions. The goldfish (McVay and Kaan, 1940) has an intestinal bulb capable of great distention and is distinct from the intestine only by size; no histological distinction was present.

\section{Intestine}

The intestine of $f$ ishes is relatively long and undifferentiated throughout its length. Weisel (1962) related the gross anatomy of the anterior intestine only, and summarized that "except for the height and shape of the plicae the intestinal tract is much the same 
in appearance from esophagus to anus". The intestine of the longnose sucker is coiled; while the squawfish intestine is S-shaped and lacks coiling. Mohsin (1961) observed the intestine of the Indian gudgeon as small and having two loops. The rectum is distinctly larger in diameter and is separated from the intestine by a sphincter. The intestine of the sea bass (Blake, 1930) forms "a loop and a half" and is about the same diameter as the rectum which is then distinguished from the intestine by "somewhat thicker walls which taper slightly toward the anus". A valve found between these two portions was considered (Blake, 1930) to be homologous to the ileocolic valve of higher vertebrates. The sea robin has three $1 \mathrm{imbs}$ of the intestine, each $1 \mathrm{imb}$ transversing nearly the entire length of the coelomic cavity. "The walls of the intestine are much more thin and flabby than those of the stomach" (Blake, 1931) but microscopic differences in the mucosal lining of the two regions was not demonstrated. The intestine of Labeo calbasu (Sehgal, 1966) "is greatly convoluted and occupies the major portion of the visceral cavity" with no demarcation between the intestine and rectum. In Labeo horie (Girgis, 1952) the intestinal swelling "passes insensibly into the intestine". Girgis (1952) considered the cyprinids to be without a differentiated mid- and hind-gut, an observation which he pointed out is concurred in by several other authors (Rogick, 1931; Jacobshasin, 1937; and Sarbahi, 1940; fide Girgis, 1952). Al-Hussaini (1946) reported the presence of a rectum and an ileorectal valve which was distinguishable internally in the bottom-feeder. In his 1947 paper on Atherina forskali, a plankton-feeder, Al-Hussaini again reported a 
distinct ileorectal valve. In the carp (Curry, 1939) "The diameter of the intestine with the exception of the large arm is almost uniform." This intestine is differentiated internally into the firm arm, which is "thicker than the remainder of $i t$, due to the greater height of the folds", and the wall again becomes thicker anterior to the anus "due to an increase of connective tissue". The intestine of the goldfish (McVay and Kaan, 1940) was smaller in diameter than the intestinal bulb and not capable of as great distention. The diameter decreased slightly toward the rectum which was distinguishable by its straight course to the anus.

\section{Histological Characteristics}

\section{Buccal Cavity}

The lining of the buccal cavity is made up of mucosa, submucosa and, in most fishes, a muscularị layer in certain areas. The histological picture of the layers varies to some extent, mostly from differences in proportions of the constituents that make up each of the layers rather than a difference in basic components. This is exemplified in the epithelial lining of the buccal cavity. Most authors (Mohsin, 1961; Weisel, 1962) described it as stratified epithelium, while others reported that it is "desquamated" in areas (Al-Hussaini, 1946; Curry, 1939), or cornified and desquamated (Girgis, 1952). It is impossible to determine the difference in structure by analysis of the literature. The basal layer is composed of columnar cells according to Weisel (1962) and Sehgal (1966) while Al-Hussaini (1946) found them to be "columnar to 
cuboidal" in the bottom-feeder, Mulloides auriflamma. Girgis (1952) labeled this layer the stratum germinativum due to the abundance of mitotic figures. Mitotic figures were recorded also by Curry (1939) in the basal layer. Mohsin (1961) found cuboidal cells above the columnar layer in the Indian gudgeon. Other authors (Girgis, 1952; Curry, 1939; Al-Hussaini, 1946) described the layer superficial to the basal layer to be fusiform in morphology and several layers of polyhedral cells above layer or layers of fusiform cells. In the bottom-feeder, Mulloides auriflamma, Al-Hussaini (1946) found intermediate layers above the basal layer to be made up of "three to four layers of pylohedral cells with subspherical nuclei showing distinct chromatin networks and nucleoli'. The lumenal surface of the epithelium is covered with flattened cells with their long axis horizontal to the stratum compactum (Curry, 1939). In Labeo horie (Girgis, 1952) and Glossogobius giurus (Mohsin, 1961) the surface cells are flattened. A polyhedral-type cell covers the surface of the buccal cavity in the bottom-feeder, Mulloides auriflamma, and plankton-feeder, Atherina forskali, (Al-Hussaini, 1946 and 1947) except on the floor of the mouth where the cells were "flattened except for the basal layer". He calls both of these "typical squamous type cells". Bishop and Odense (1966) reported the "epithelial cells become more flattened as they reach the surface"'. In the goldfish (McVay and Kaan, 1940) the pharyngeal epithelium is "apparently stratified columnar of a specialized type". Girgis (1952) reported the total number of layers to be 
6 to 14 while Al-Hussaini (1946) found 10 to 12 in the bottom-feeder, Mulloides auriflamma, and an average of seven layers in the planktonfeeder, Atherina forskali. Weisel (1962); Mohsin (1961); Sehgal (1965); and Curry (1939) reported that the epithelium is stratified but did not give a numerical count of the layers. The epithelial lining (Weisel, 1962; Sehgal, 1965; Girgis, 1952) contains taste buds and goblet cells or mucous cells. The description of the taste buds given by Girgis (1952) conforms closely with that of other authors. He stated these to be: ". . flaskshaped structures which usually rest on papillary evaginations of the subepithelial connective tissue. . . Two kinds of cells make up the taste buds; gustatory cells in the central part of the bud which are fusiform and have a long process extending from each cell to the surface of the epithelium and sustenacular cells which form an outer zone around the gustatory cells."

There is also general agreement on the location of these cell types in the epithelial lining. In Labeo horie the taste buds are found on the crests of folds and never in the crypts (Girgis, 1952). Al-Hussaini (1947) confirms this for the plankton-feeder, Atherina forskali, but does not mention it in reference to the bottom feeder, Mulloides auriflamma. In the cod, taste buds were on the tops of the folds "except on the tongue which has a flat surface" (Bishop and Odense, 1966). "Taste buds are usually found on evaginations of the stratum compactum" in the carp (Curry, 1939). Sehgal (1966), however, reported the taste buds were found on the tops of the folds as well as in the crypts. Weisel (1962) found few mucous cells in the epithelium of the longnose sucker and the squawfish. The presence of epithclial mucous 
cells is only mentioned by Mohsin (1961). In Labeo calbasu (Sehgal, 1966), the mucous cells are numerous in the epithelial lining of the buccal cavity. Girgis (1952) called these "goblet cells" and noted they were frequent and the number increased posteriorly. He noted they were usually pear-shaped and varied in abundance with the region and age--being most numerous in the posterior region of the buccal cavity of young fish. In the bottom-feeder, Mulloides auriflamma, (Al-Hussaini, 1946) goblet cells were not numerous. He described them as being "pyriform and each has a small flattened nucleus almost disposed in the base of the cells. . a cell measures 16 by $8 u$ and opens on the surface by a relatively wide pore". In this fish, the cells are never found on the crests of papillae but are on the sides of the crypts. The mucous cells are found at the crests of folds and are "an important part of the epithelium" in the plankton-feeder, Atherina forskali, (Al-Hussaini, 1947) "none are found at the bases of the crests" contrary to what he had found on the bottom-feeder, Mulloides auriflamma. Both Bishop and Odense (1966) and Al-Hussaini (1946) mentioned that goblet cells distorted the epithelium. In the goldfish (McVay and Kaan, 1940), the mucous cells are "closely packed" and are not as numerous at the crests of the mucosal folds and "in some cases, were entirely absent".

\section{Esophagus}

The wall of the esophagus is composed of mucosa, submucosa, and muscularis and many fishes exhibit distinct variation in histological 
detail of the esophagus musculature compared with the higher vertebrates. The esophagus of the longnose sucker and the squawfish of Weisel's study (1962) are similar histologically. In both fishes, the epithelium was described as oval epithelial cells, giving it "a foamy appearance", and mucous cells with no taste buds present. Mohsin (1961) found the esophageal mucosa was folded with the epithelium consisting of 2 to 3 layers of cells full of mucin. "Simple mucous glands" were seen next to or below the mucous cells. The esophageal epithelium in the sea bass (Blake, 1930) consists of supporting columnar and goblet cells characterized by the surface layer of cells resting on strata of supporting cells at the apices of the folds, especially in the anterior region. Blake (1930) pointed out that Green (1913) found this same condition in the salmon and considered the supporting cells to be a transformation stage between the stratified epithelium of the mouth and the simple condition of the rest of the gut. Blake (1930) gave a detailed description of the two types of cells reporting the distal portion of the goblet cells, which were the larger of the two forms, appeared granular, and that "often these cells are so thickly crowded together that some are pushed down below the superficial layer. . . Within the deeper folding of the epithelium these cells are of ten closely packed together and distorted and come then to cover the entire surface."

The epithelium of the sea robin (Blake, 1936) is stratified with fewer layers posteriorly. Mucous cells were found within the epithelium and "become fewer in number as the stomach is reached". A complexity 
of folds was described and Blake (1936) believed "at least the larger folds were permanent due to supporting connective tissue", and he also noted a cellular differentiation occurring in different regions of a fold. In Labeo calbasu (Sehgal, 1966) the epithelium is stratified at the tips of folds and "a large number of goblet cells form a continuous layer" at the sides of the folds. Anteriorly only mucous cells could be distinguished, and posteriorly the epithelium became columnar. The mucosa was completely folded with stratified epithelium covering the tips of the major folds, while mucous cells formed a "more or less continuous layer'l at the sides of the folds in Labeo horie (Girgis, 1952). The basal layer of epithelium was "more or less cuboidal", with thin layers of polygonal cells above them and a layer or layers of goblet cells at the sides of the folds, or polygonal cells, followed by one or two layers at the tips. Al-Hussaini (1946 and 1947) reported the esophageal epithelium in Mulloides auriflamma and Atherina forskali was folded into primary, secondary, and tertiary folds covered with 3 to 4 layers of stratified epithelium which gradually becomes columnar and the columnar cells appear first on the tops of the folds. In comparison, Blake (1936) also found this condition as did Dawes (1929) and Ghazzawi (1935); Rogich found the reverse of this condition (fide Al-Hussaini, 1946). In the bottom-feeder, Mulloides auriflamma, and the plankton-feeder, Atherina forskali, mucous cells become fewer in number in the anterior esophagus and are entirely absent in the posterior esophagus (Al-Hussaini, 1946 and 1947). In the cod, basal layer of the stratified squamous epithelium of the esophagus is columnar and the cells become flattened toward the surface (Bishop and 0dense, 1966). 
The epithelium is supported by a layer of dense connective tissue in both the longnose sucker and the squawfish (Weisel, 1962). The submucosa of the Indian gudgeon (Mohsin, 1961) "is well developed and compact".

The submucosa is composed of connective tissue interwoven with blood vessels and nerves (Blake, 1930, 1936; Girgis, 1952; Al-Hussaini, 1946 , 1947). The arrangement of the connective tissue units varies to some extent. For example, Blake (1936) called it "areolar type. . . (with) considerable variation in the density", while Weisel (1962) described it as "a layer of compact connective tissue and next to a layer of loose lamina propria". Longitudinal muscle fibers, often described as being in bundles, were reported to penetrate the submucosa (Blake, 1930, 1936; Al-Hussaini, 1946, 1947; and Bishop and Odense, 1966). Mohsin (1961), however, called these "muscle bundles" the longitudinal muscle layer. Blake (1930), in describing the sea bass, stated the long bundles of muscle do not connect with the circular muscle layer and thus, "the esophagus does not possess longitudinal fibers". In the sea robin, Blake (1936) stated the isolated bundles of muscle fibers were "apparently derived from the circular muscle coat". The muscle bundles within the submucosa vary in location from next to the circular muscle layer to deep within the folds (Blake, 1930, 1936; Sehga I, 1966).

The tunica muscularis of the esophagus in all fishes is composed of striated muscle fibers which are arranged into a circular layer and 
in some fish a longitudinal layer. Blake (1930) reported the sea bass has only a layer of striated circularly arranged muscle fibers. In the sea robin, Blake (1936) reported an inner circular and an outer longitudinal coat just beneath the serosa, with the longitudinal layer being composed of only a few layers of muscle fibers. Weisel (1962), Al-Hussaini (1946), and Curry (1939) also found only one layer of muscle in the tunica muscularis. Girgis (1952), Mohsin (1961), and Bishop and Odense (1966) described two muscle layers, an inner longitudinal layer, and an outer circular layer. Al-Hussaini (1947) described two coats, "an anterior circular and an inner longitudinal" layer. From his illustration it seems the longitudinal layer is on the lumenal side of the circular layer.

The serosal coat is composed of a layer of squamous epithelium and a varying amount of fibrous connective tissue (Blake, 1930, 1936; Al-Hussaini, 1946, 1947; Bishop and Odense, 1966).

\section{Stomach}

The stomach, when present, is composed of four layers, mucosa, submucosa, muscularis, and serosa. A stomach was reported to be present in the Indian gudgeon (Mohsin, 1961), the sea bass and the sea robin (Blake, 1930, 1936), the bottom-feeder, Mulloides auriflamma, (Al-Hussaini, 1946) and the cod (Bishop and Odense, 1966). In Labeo horie, a bottom-feeder, (Girgis, 1952) and Atherina forskali (Al-Hussaini, 1947) there are intestinal swellings. 
The gastric mucosa of the Indian gudgeon (Mohsin, 1961) is highly folded and consists of " 2 or 3 layers of columnar epithelial cells"; simple gastric glands are found in the mucosa. Mohsin (1961) did not consider the gastric region to be well defined. Blake (1930) distinguished a cardiac region, with gastric glands, and a relatively small aglandular region in the posterior third of the stomach. In the cardiac region the epithelium is composed of long columnar cells with a "thick layer of gastric glands of the tubular type".

The epithelium of the pyloric region is much less folded and there are no gastric glands. The epithelial cells are longer and more slender. In the sea robin, Blake (1936) reported the gastric mucosa was similar to that found in the sea bass. The gastric mucosa of the bottom-feeder, Mulloides auriflamma, (Al-Hussaini, 1946) is similar to that described by Blake (1930) for the sea bass. Bishop and Odense (1966) found a rapid transition from the stratified epithelium of the esophagus to the columnar epithelium of the stomach and noted compound glands instead of the simple glands found by Blake (1930) and Al-Hussaini (1946).

Mohs in (1961) reported the submucosa was "well developed and compact" in the Indian gudgeon. Blake (1930) found the submucosa of the sea bass was of variable thickness and proposed "the very loose character of the areolar tissue here bespeaks adaptation to the various changes of the gastric epithelial folds during the different stages of digestion". In the sea robin the gastric submucosa "forms a comparatively thick and well-differentiated layer"', with the thickness varying somewhat but the "cellular and intercellular elements remaining about the same. Al-Hussaini (1946) found the submucosa was composed of 
areolar connective tissue and was most developed in the cardiac region.

The tunica muscularis of the Indian gudgeon (Mohsin, 1961) was divided into an inner circular layer consisting of "thickly set fibers" followed by an "intermediate or myenteric layer". The sea bass (Blake, 1930) has a circular layer next to the submucosa and an outer longitudinal layer. Striated fibers were found in the circular layer in the anterior part of the stomach only. No striated fibers were found in the longitudinal layer, and Blake (1930) theorized "their absence in the cardiac end is connected with the fact that this layer does not occur in the esophagus'". The longitudinal layer is thin at the anterior end but then increases in thickness. In the sea robin (Blake, 1936) there are two coats of muscle in the tunica muscularis as described for the sea bass. Blake (1930) also reported "the intermuscular plexus of Auerbach" is between the two layers, and the circular layer is not highly vascularized as is the longitudinal layer. Al-Hussaini (1946) found two muscle layers throughout the length of the stomach of Mulloides auriflamma. In describing the layers in the cardiac region he stated "the circular layer is slightly thicker than the longitudinal. . "while in the pyloric region the "circular layer is responsible for the formation of the greater part of the wall'. He noted connective $\mathrm{t}$ issue and blood vessels between the muscle fibers in both regions. Bishop and Odense (1966) stated that the circular layer of striated muscle fibers of the esophagus are gradually replaced by smooth muscle 
fibers in the stomach of the cod. "The inner longitudinal layer of striated muscle fibers of the esophagus disappears and the outer longitudinal layer of smooth muscle fibers appears".

Al-Hussaini (1946) reported the serosa of the stomach is similar to that found in the esophagus but the subserosal connective tissue is more developed and more vascularized. Blake (1930) found the serosa is "composed of a single layer of typical flattened serosa cells" in the sea bass. He noted it is "perhaps" thicker than normal in other vertebrates. In the sea robin, Blake stated "The serosa is in all respects like that of other carnivorous fishes."

\section{Intest ine}

There is great variation in structure of the intestine of fishes. Many without a stomach have an enlargement in the anterior intestine which is referred to as either an intestinal swelling or intestinal bulb (Girgis, 1952; Al-Hussaini, 1947). At the anterior end of the intestine "the development of blind outgrowths, the pyloric caeca. . . is found in many fishes, particularly among the Actinopterygli" (Barrington, 1957): "The long and comparatively thin pyloric caeca" show the same histological layers as those of the intestine (Al-Hussaini, 1946). Blake (1936) reported Oppel (1896), Gulland (1898), and Greene (1913) had stated "pyloric caeca are of the same structure as the region of the gut whence they are diverticula" and found this in the sea robin.

It is generally agreed the mucosal epithelium of the intestine is composed of columnar cells and goblet cells throughout most of the 
length of the intestine (Weisel, 1961; Blake, 1936; Bishop and Odense, 1966). The goblet cells were considered by Blake (1936) as derived from the "undifferentiated columnar cells". Blake $(1930,1936)$ and Girgis (1952) described the columnar cells as "tall" and having a "top plate or striated border". Al-Hussaini (1949) proposed the epithelial cells be termed other than "columnar" or "cylindrical" because they are not straight but bent (fide Girgis, 1952). Granular cells, identified as lymphocytes, are found within the mucosal epithelium as lymphocytes (Blake, 1930, 1936; Sehgal, 1966; Girgis, 1952). Al-Hussaini (1946) reported these cells penetrated the epithelium to the level of the top plate. In the sucker and squawfish, Weisel (1962) stated "there are no crypts or multicellular glands in the walls of the tract". Several authors (Blake, 1930; Mohs in, 1961; Sehgal, 1966; Girgis, 1952; and Al-Hussaini, 1946, 1947) did not mention occurrence of either glands or crypts in their description of the intestine. Blake (1936) noted "sections through the folded mucosa may simulate simple or compound tubular glands" but he did not find any difference in the cell type. As reported by Curry (1939) crypts, termed "plasmode", were described by Pictet (1909) in cypridids but Curry (1939) was unable to find the "plasmode".

A submucosa is not differentiated from the lamina propria (Weisel, 1962; Blake, 1930, 1936; and Al-Hussaini, 1946, 1947). The lamina propria was described by Weisel (1962) as "loose and areolar. . (and) continues to the muscularis"'. In other fish a submucosa is reported (Mohsin, 1961; Sehgal, 1964; Girgis, 1952). In Glossogobius 
giuris the submucosa "consists of thick strands of connective tissue fibers" (Mohsin, 1961).

A circular muscle layer on the lumenal side of a longitudinal muscle layer is characteristic of the tunica muscularis of the intestine and the pyloric caeca (Blake, 1930, 1936; Al-Hussaini, 1946, 1947; Curry, 1939) except in Glossogobius giuris (Mohsin, 1961) which has an "intermediate or myenteric" layer between the circular muscle layer and the longitudinal layer. Al-Hussaini (1946) stated the ratio of the thickness of the circular muscle layer to the longitudinal layer was 7:5, but subject to variations. Other authors reported the circular layer is thicker than the longitudinal layer (Girgis, 1952; Sehgal, 1965; Curry, 1939) and agreed the muscle fibers are of the smooth muscle type except in fishes without a stomach in which some striated fibers were found in a transitional area between esophagus and intestine.

The serosal covering of the intestine (Blake, 1930) is composed of a layer of cuboidal cells and a limited amount of connective tissue. Other authors (Al-Hussaini, 1946, 1947; Mohsin, 1961; Curry, 1939) reported the epithelial cells were squamous. The accompanying connective tissue varies from fish to fish and the area of the intestine (Girgis, 1952; Al-Hussaini, 1946, 1947; and Curry, 1939).

MATERIALS AND METHODS

Channel catfish, Ictalurus punctatus, were seined from the fisheries ponds at the Tuttle Creek Fisheries Research Laboratories throughout the summer months and in the winter when the ice covering 
permitted. Fish were paralyzed by pithing the spinal cord, allowing the collection of tissue while it was still being bathed by blood. Selected animals were dissected for gross anatomical relationships and measurements. Tissues were taken from each of the divisions of the digestive tract (Fig. 1) and immediately placed in Bouin's fixative. Some of the tissue samples were infused with fixatives either through the blood vasculature system or by injecting fixative directly into the lumen of the digestive tube. Buffered neutral formalin (10\%) and chromic acid fixatives were used, but neither of these gave good cellular detail. Bouin's fixative was used routinely in later studies. The fixative was used either at room temperature or chilled to $5^{\circ} \mathrm{C}$ to retard autodigestion of the mucosal layer. All tissues were left in the fixative a minimum of 24 hours after which they were washed in running water and then dehydrated for paraffin embedding. Serial sections were cut at 8 or $10 \mathrm{u}$ from each tissue sample and three slides were prepared with a minimum of six sections per slide.

Three staining procedures were used routinely. Nuclei were stained with Harris' hematoxylin in all three staining procedures. Acid fuchsinorange-G was used for a general histological picture. A PAS reaction was used on the second slide for mucopolysaccharides, and Mason's trichrome was used for connective tissue. Mallory's triple stain was used in some preparations as an alternate to Mason's trichrome. Orcein was used on one series of slides to stain for elastin.

The slides were examined with a light field microscope and descriptions were made from these observations. Photographs were taken to record histological details in a convenient form. 


\section{EXPLANATION OF PLATE I}

Fig. 1. Dissection of a seven pound channel catfish with divisions of the digestive tract delineated by dotted 1 ines.

Key to abbreviations used in Plate I:

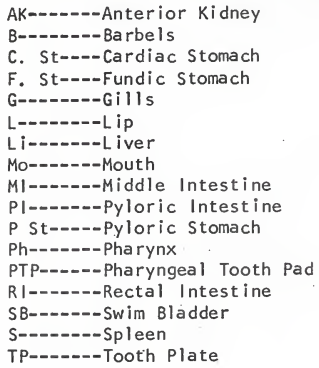




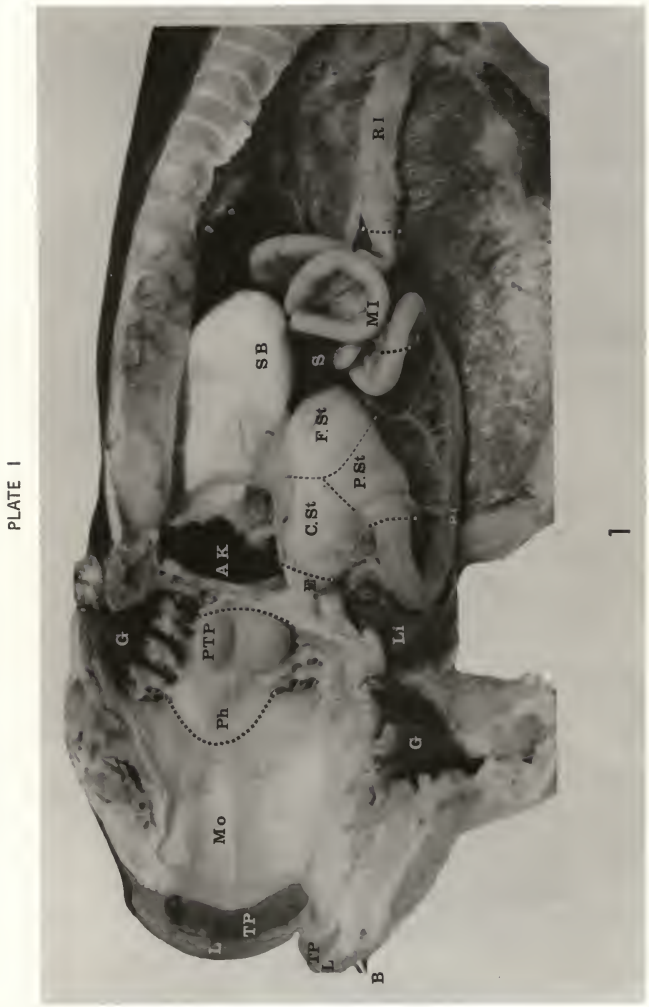




\section{RESULTS}

\section{Gross Ana tomy}

\section{Oral Cavity and Pharynx}

The channel catfish is described as omnivorous (Cross, 1967) and shows characteristics of both predaceous and grazing fishes. The oral cavity is flattened dorsoventrally. The mouth is anteriorly terminal and is directed downward; it is not highly protrusible and is bounded by upper and lower jaws. The lips are rudimentary with barbels extending from the corners and from the middle of the lower lip. Pads of cardiform teeth lie internal to the upper and lower lips with the lower pad split in the middle (Fig. 1). These pads form elongated curved bands. A flap-like fold of the oral mucosa arises from the posterior edge of the upper and lower jaw teeth and covers a depression in the dorsal and ventral walls of the oral cavity. A prominent mucosal fold on the roof of the mouth extends to the pharynx. Lesser folds are found throughout the oral cavity. The tongue is rudimentary.

A short pharynx begins at the first gill cleft which is the dividing line between the buccal and pharyngeal cavity (Bishop and Odense, 1966). The lateral boundaries of the pharynx are formed by the three gill bars, each of which bears two rows of short cone-shaped gill rakers. The anterior row of each set of gill rakers is the most developed (Fig. 1). The roof of the dorsal pharyngeal wall is formed by the palatine bones with transverse mucosal folds extending from the 
first two gill bars, and curving anteriorly and then connecting with the fold from the first two gill bars of the opposite side. Two somewhat rounded "tooth" pads are present on the dorsal wall, lateral to the midline and medial to the posterior gill bars (Fig. 1). These tooth pads are moveable primarily in a dorso-ventral and anterior-posterior direction. The ventral wall of the pharynx is formed by the union of the gill bars from either side. A mucosal fold on the floor of the pharyngeal cavity is formed between the gill bars. The folds between the first two pairs of gill bars extend transversely across the floor of the pharynx but the folds formed by the last pair of gill bars are interrupted by two triangularly-shaped pads of "teeth". These, along with the dorsal pads directly above, are the pharyngeal teeth and are of the cardiform type.

\section{Esophagus}

The esophagus is a short tube which begins at the posterior edge of the pharyngeal tooth pads. The esophagus extends caudoventral from the pharynx, passes immediately through the transverse septum in the midline of the body ventral to the anterior kidneys and dorsal to the liver. Posterior to the anterior kidneys, the esophagus lies between and ventral to the swim bladders and there joins the anterior end of the stomach. Only internally can the transition from esophagus to stomach be determined by the change in size and number of mucosal folds on the internal surface. The folds of the esophagus are more plentiful and finer than those in the stomach.

\section{Stomach}

The stomach of the channel catfish is J-shaped and lies on the left side. The stomach can be divided into cardiac, fundic, and pyloric portions. The cardiac part is continuous with the esophagus and is coneshaped, the base of the cone connected, in part, with the fundus and, in part, with the pyloris. The fundus, an extension of the most caudal part 
of the cardiac region, is considered here to be a separate division of the stomach because of its pouch-like shape and because of the lack of mucosal folds on the internal surface. The cardiac and fundic regions comprise roughly two thirds of the entire stomach and are lined with heavy rugae except for the lower part of the fundus. The pyloric portion extends craniad from the cardiac and fundic parts of the stomach and then decreases in diameter to connect with the anterior part of the intestine. A pyloric valve is formed by folds in the mucosa of the pyloris, supported by a heavy band of circular muscle.

\section{Intestine}

Caudad to the pyloric valve, the intestine is essentially uniform in structure both grossly and histologically. It would be misleading, therefore, to separate the intestine of the channel catfish into the classical divisions of duodenum, jejunum, ileum, and large intestine. For purposes of labeling, that part of the intestine which begins at the pyloric valve and continues posteriorly without coiling will be called pyloric intestine (Fig. 1). The middle portion of the intestine, which is a coiled mass, will be termed the middle intestine (Fig. 1). The posterior, or rectal intestine, lacks coils and lies in the dorsal part of the body cavity; it curves ventrally to the anus (Fig. 1). The serosa of this part of the intestine is finely folded giving this region $a^{w}$ rinkled appearance.

\section{Histological Characteristics}

\section{Esophagus}

The transition from pharynx to esophagus is characterized by the disappearance of taste buds and appearance of the circular muscle layer of the muscularis externa. Some taste buds are found, however, in the 
anterior end of the esophagus on the tips of mucosal folds (Fig. 4). The mucosa of the esophagus is organized into extensive primary, secondary, and tertiary folds. The primary or longitudinal folds are formed by the submucosa and are covered on both sides with layers of the mucosa (Fig. 2); these folds decrease in height when the esophagus is fully distended. Secondary and tertiary folds are formed by the mucosal layers, with the lamina propria of one side of the fold lying against that of the other side. There is no directional orientation of the secondary and tertiary folds and they are entirely lost when the esophagus is distended.

Non-cornified, stratified squamous epithelium lines the lumen. The epithelial layer of the folds is between 50 and $100 \mathrm{u}$ thick at the apex, and 40 to $80 \mathrm{u}$ at the base. The epithelium does not change greatly in thickness with distention of the organ. PAS-positive, mucous-secreting cells are numerous throughout the epithelial layer; the apical ends of these cells extend to the luminal surface of the epithelium (Fig. 3). In fish taken from warm water the mucous secreting cells are abundant in the upper esophagus becoming progreșsively more sparse caudally; in fish taken from cold water numerous mucous secreting cells occur throughout the ep i thel i um.

Beneath the epithelium is a distinct basement membrane external to which interlacing collagenous fibers form the lamina propria. Histiocytes and fibrocytes are interspersed among the fibrous matrix. A discontinuous layer of longitudinal muscle fibers (Fib. 2) constitutes the muscularis mucosa which is formed into bundles by 
Fig. 2. Transverse section of the esophagus of a fish taken from cold water. Note the numerous goblet cells within the epithelial layer. Longitudinal muscle bundles can be seen within the submucosa. Stained with hematoxylin, Acid Fuchsin and Orange G. 50X.

Fig. 3. Transverse section taken at the junction of the esophagus and stomach. The stratified epithelium, characteristic of the esophagus, is seen at the top of the fold and is replaced by columnar epithelium at the bottom of the fold. A gastric gland is seen at the bottom of the fold. Stained with hematoxylin, Acid Fuchs in and Orange G. 100x.

Fig. 4. An enlargement of a fold of the esophageal epithelium with a taste bud at its tip comprised of sustentacular cells and hair cells. Stained with hematoxylin, Acid Fuchs in and Orange G. 100X.

Fig. 5. Cardiac region of the stomach transversely sectioned showing mucosal, submucosal, and muscularis externa. Stained with hematoxylin, Acid Fuchs in and Orange G. $50 x$.

Fig. 6. Section of the pyloric region of the stomach. Note the absence of the gastric glands beneath the epithelial lining. Stained with hematoxylin, Acid Fuchsin and Orange G. 50X.

Key to abbreviations used in Plate II:

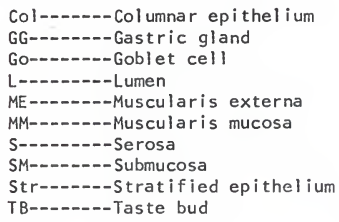


PLATE | |
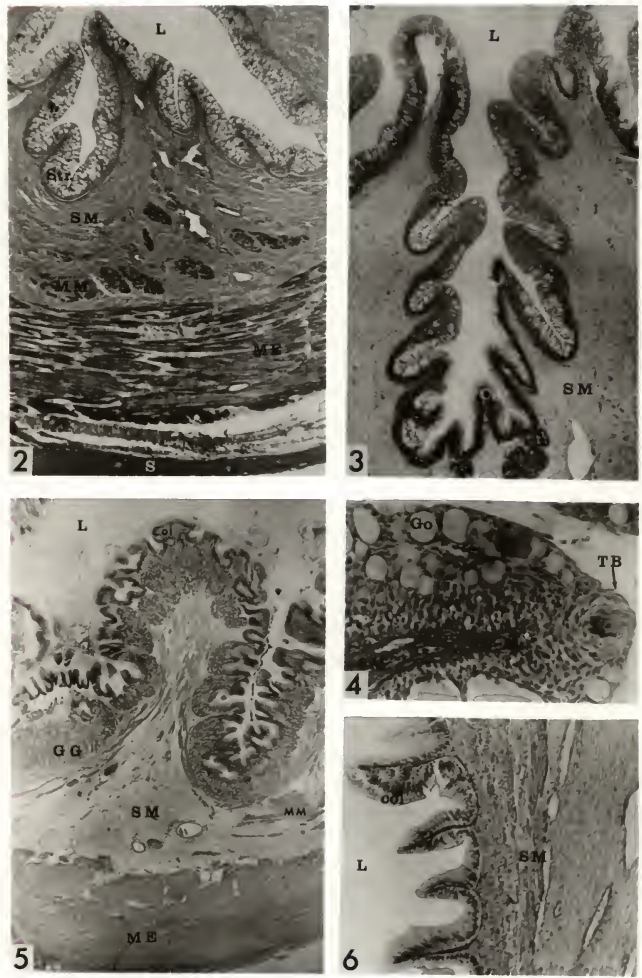
interweaving fibrocytes and collagen fibers. These bundles range from a single fiber to 100 or more fibers per bundle and are located principally at the periphery of the submucosa although some are located near the inner limits of the lamina propria. The channel catfish does not have mucosal or submucosal glands in the esophagus.

The submucosal matrix is composed of coarse, densely-arranged collagen fibers. A network of blood vessels and lymphatic vessels interweave the fibrous mucosa. Some of the capillaries, originating in the submucosa, continue into the lamina propria providing a loose capillary net adjacent to the basement of the luminal epithelium. The blood vessels range in size from arteries and arterioles down to capillaries. Occasional nerve fibers are also found in the submucosa.

The muscularis externa is formed entirely of a continuous layer of circular muscle fibers; longitudinal fibers are completely absent. The muscularis externa is thickest where the esophageal lumen is smallest and becomes thinner as the esophagus is distended. While striated muscle is the predominant muscle type between the posterior pharynx and the junction of the esophagus and stomach, some smooth muscle fibers are present. The striated fibers exhibit cross striations and Conheim's fields. At the transition from esophagus to stomach, the striated muscle fibers are replaced by smooth muscle which, at this point, begins to be overlain by the outer longitudinal muscle layer of the muscularis externa of the stomach. Blood and lymph vessels and nerves transverse the muscularis layer and form a network within it. 


\section{Stomach}

The wall of the stomach consists, from inside outward, of mucosa, submucosa, muscularis externa, and serosa (Fig. 5).

At the junction of the esophagus and the stomach, the luminal epithelium undergoes an abrupt change from the stratified squamous type of the esophagus to a simple columnar type which persists throughout the stomach. The epithelial cells average $30 \mathrm{u} \mathrm{high}$ and $5 \mathrm{u}$ wide at the luminal ends, slightly narrower at the base. The luminal ends of the columnar cells are filled with an intensely staining PAS-positive secretion and are so extensive that a red band encircles the lumen in a PAS-stained preparation. Ciliated columnar cells are present in the upper portion of the stomach in patches and become more abundant toward the pyloric end. The mucosa of the cardiac and fundic regions of the stomach contains gastric glands (Fig. 5) while the mucosa of the pyloric region lacks gastric glands (Fig. 6). The glands in both cardiac and fundic regions are predominantly simple coiled tubular structures but some are branched. Ducts from the gastric glands empty into the base of mucosal fovoelae (Figs. 7 and 8 ). The cuboidal cells have rounded vesticulate nuclei near the basement membrane; each nucleus with a distinct nucleolus. The cytoplasm of the gland cells is finely granular and shows light PAS-positive reaction near the gland lumen. Collagen fibers from the lamina propria extend between the glands. At least two thirds of the mass of the mucosa in the upper regions of the stomach is formed by the gastric glands; the epithelial fovoelae comprise the lumenal third. In the pyloric region, however, the fovoelae are deeper and no glands are present (Figs. 9 and 10 ). 


\section{EXPLANATION OF PLATE III}

Fig. 7. The mucosal layer from the cardiac region of the stomach stained with PAS. The lumenal ends of the columnar cells stained intensely PAS+. A duct from the gastric glands empties into the base of a crypt. Stained with PAS and hematoxylin. 100x.

Fig. 8. The mucosal layer from the cardiac region of the stomach. Gastric glands empty into the base of the crypt. Stained with hematoxylin, Acid Fuchsin and Orange G. 200X.

Fig. 9. Mucosal layer of the pyloric region of the stomach. Note the absence of the gastric glands. Stained with hematoxylin, Acid Fuchs in and Orange G. 100X.

Fig. 10. Mucosal layer of the pyloric region of the stomach stained with PAS. The intensely stained lumenal ends of the columnar cells is characteristic of the pyloric stomach. stained with PAS and hematoxylin. 100X.

Abbreviations used in Plate III:

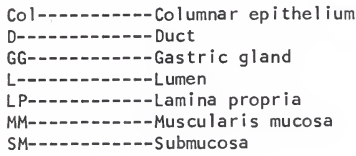


PLATE $\|$ ।
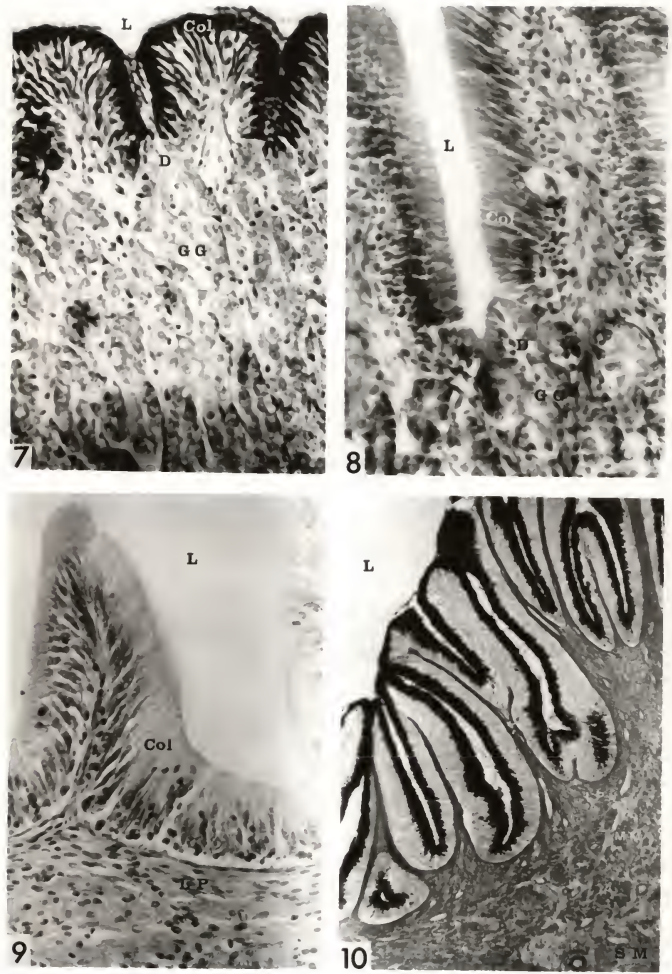
In the region of transition from esophagus to stomach, the mucosal folds decrease in number from the 10 to 14 of the esophagus to 8 to 10 in the cardiac and fundic regions of the stomach. As the number decreases, the primary folds become heavier and deeper. In the transition from fundic to pyloric region, the mucosal folds become thinner and lower but not more numerous. This condition may result from a thinner mucosa in the pyloric region. The primary foldings in both the upper and lower stomach are formed by the layers of the mucosa covering a projection of the submucosa. Lesser foldings are formed throughout the stomach entirely by mucosal layers.

The lamina propria of the stomach is composed of collagen fibers and some elastic fibers. In the upper parts of the stomach the lamina propria projects between gastric glands arranging them into bundles (Fig. 3). In the cardiac and fundic parts of the stomach, the lamina propria is a thin layer but with the transition into the pyloric region, it increases in thickness and definition.

At the anterior end of the stomach a thin discontinuous layer of smooth muscle fibers, the muscularis mucosa, is continuous $w i$ th that of the esophagus and lies immediately external to the lamina propria. As the transition from glandular to the non-glandular mucosa occurs, the muscularis mucosa thickens and, in the pyloric region, becomes a more continuous layer. Fibers of the muscularis mucosa extend into the primary mucosal foldings and into some of the lesser foldings. 
The submucosa of the stomach is a continuation of the dense submucosa of the esophagus. In the cardiac part of the stomach the submucosal connective tissue becomes thin, areolar, and light staining. It loosely connects the relatively thick glandular mucosa to the muscularis externa. In the pyloric region, the submucosa is thicker and less areolar, composed of collagen and elastic fibers interwoven into a connective tissue matrix in which histocytes, fibrocytes, and lymphocytes are dispersed.

The striated circular muscle layer of the esophagus occurs outside an inner circular muscle layer of the stomach at the transitional zone between esophagus and stomach. At this transitional zone the circular, striated layer of the esophagus becomes interwoven with longitudinal smooth fibers forming the longitudinal muscle layer of the stomach. The circular muscle layer remains inside. In the lower part of the stomach a discontinuous layer of fibers comprises an inner oblique layer. The circular muscle is the thickest layer of muscle in the stomach, but all three layers vary in thickness depending upon the amount of distention present.

A thin layer of connective tissue fibers covered by a single layer of mesothelial cells form the serosal coat of the stomach. Blood vessels penetrate the serosa at the mesogaster and form a complex vascular network in the stomach wall. Capillaries interweave within the layers of the stomach wall and penetrate to the basement membrane of the mucosal epithelium. Nerve fibers also 
penetrate the stomach wall from the dorsal mesentery and form complexes within the stomach wall.

\section{Intest ine}

The wall of the intestine consists, from inside outward, of mucosa, submucosa, muscularis externa, and serosa (Figs. 11 and 12).

The intestinal mucosa from the pyloric intestine through the rectal intestine is lined by simple columnar to a pseudo-stratified columnar epithelium. The epithelial cells have a striated border on the apical ends and the vesiculate nuclei are round to ovoid, with each possessing a distinct nucleolus. Mucous secreting goblet cells, as indicated by a PAS-reaction, are few in number in the pyloric intestine but increase in number caudally (Fig. 14). Crypts are formed throughout the length of the intestine by the primary and secondary folds of the mucosa. The crypts are deepest in the pyloric intestine and become progressively more shallow in the caudal regions. The crypts are entirely obliterated when the intestine is distended. In the pyloric and middle intestinal regions, shallow simple multicellular glands open into the crypts from their base and walls. Those glands cut in longitudinal section are only a few cells deep while those cut in cross section are seen as round tubules lined with epithelial cells (Fig. 13). The epithelial cells that form the glands are of the same type as those lining the intestinal lumen and in all three stains routinely used they stain with the same intensity as the epithelial cells lining the lumen of the gut. The basement membrane is at the base of the 
Fig. 11. The pyloric intestinal wall transversely sectioned. The mucosal, submucosal, muscularis externa and serosal layers are evident. Stained with hematoxylin, Acid Fuchsin and Orange G. 50X.

Fig. 12. The rectal intestinal wall transversely sectioned. The mucosal, submucosal, muscularis externa and serosal layers are evident. Note the increase in thickness of the muscularis externa. Auerbach's plexuses are seen between the longitudinal and circular muscle layers of the muscularis externa. Stained with hematoxylin and Mason's Trichrome. $50 x$.

Fig. 13. The mucosal layer of the pyloric intestine with a transverse section through an intestinal gland. Stained with hematoxylin, Acid Fuchsin and Orange G. 100x.

Fig. 14. The mucosal layer of the rectal intestine. Goblet cells are stained intensely with PAS. Stained with PAS and hematoxylin. 100x.

Key to abbreviations in Plate IV:

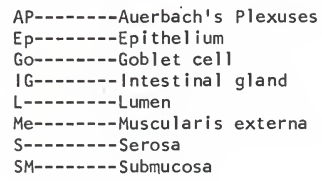


PLATE IV
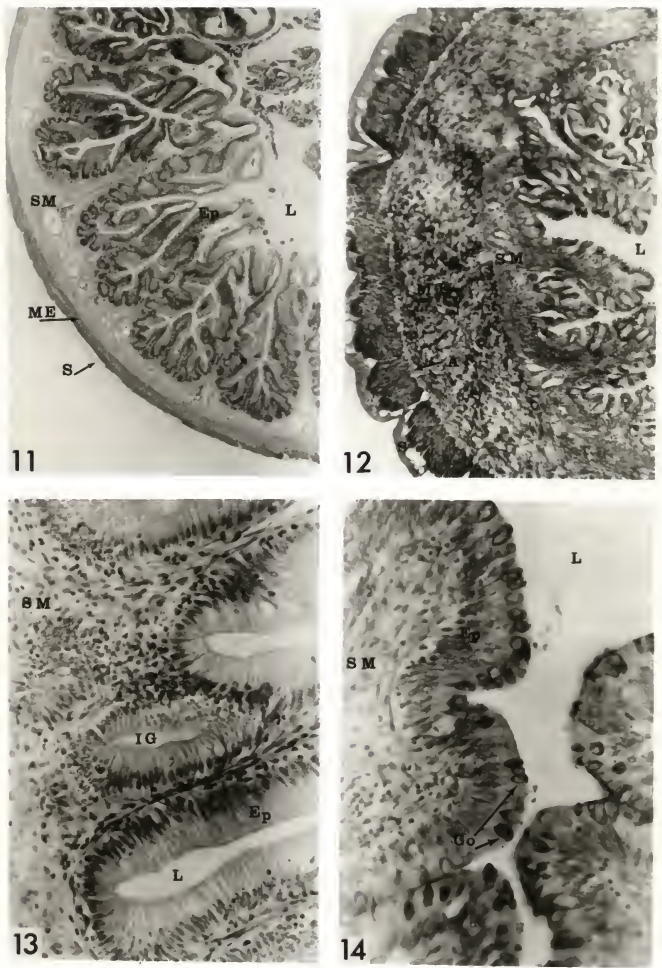
epithelium with a thin lamina propria formed internal to it by loosely arranged collagen fibers. There is no muscularis mucosa in the intestinal tract. Brunner's glands or submucosal glands typically found in the higher animals are not present as such in the channel catfish intestine.

The submucosa of the intestine is formed of collagen and elastic fibers. In the pyloric intestine, the submucosa is loosely arranged while in the middle intestine the collagen fibers are denser. The submucosa also becomes thicker or greater in mass as it progresses from craniad to caudad. In the middle intestine, the collagen fibers of the submucosa immediately beneath the mucosa are thinner with more nuclei present. The collagen fibers at the periphery of the submucosa are thicker and appear to be in bundles. The use of Orcein stain indicated elastic fibers are sparse in the submucosa. Blood vessels and nerves penetrate the intestinal wall from the supporting mesentary. A complex and extensive vascular network is present in the intestinal submucosa from the duodenal area through the colon.

The muscularis externa is divided into two well-defined layers of smooth muscle, an inner circular layer and an outer longitudinal layer (Fig. 12). Connective tissue components and blood vessels penetrate into and through the two layers. Nerve fibers form Auerbach's plexuses between the layers.

The serosal coat of the intestine is composed of a thin layer of collagen fibers some of which project between the fibers of the 
longitudinal muscle layer. The fibrous portion of the serosal coat is thicker in the rectal intestine. The collagen fibers are covered by a sheet of mesothelium. The serosal coat completely encircles the intestine and is continuous with the supporting mesentery.

\section{Pancreas}

Nodules of pancreatic tissue are found along the blood vessels in the mesenteries of the gut. A significantly larger nodule was consistently found in the gastrohepatic mesentery in close proximity to the common bile duct. This nodule may be 5-6 mm wide and 9-10 $\mathrm{mm}$ long in a large fish while the small nodules are never over a few millimeters in diameter. The largest concentrations of pancreatic tissue is found around the gall bladder and bile duct in the gastrohepatic mesentery and within the liver in proximity to the hepatic ducts (Fig. 15).

On gross examination the pancreatic tissue appears to consist of isolated masses of tissue. Histologically these masses are found to connect by fine projections of pancreatic cells to the other pancreatic tissue encircling the common bile duct. Often the connecting projections are only a few cells in diameter, arranged into tubules with extremely small lumen (Fig. 18). They are often collapsed on a prepared slide to show no lumen. The pancreatic tubules join the common bile duct a short distance before the duct empties into the pyloric intestine (Fig. 15). 


\section{EXPLANATION OF PLATE $V$}

Fig. 15. Pancreatic tissue is seen within the liver capsule, surrounding the bile duct. Stained with PAS and hematoxylin. 100x.

Fig. 16. Acinar cells darkly stained with PAS interspersed with islets of Langerhans. 500X.

Fig. 17. Section of the pyloric intestine, at the point where the common bile duct enters it, and a pancreatic nodule in the upper middle of the picture within the hepatoduodenal mesentery. Stained with Mason's Trichrome. $50 x$.

Fig. 18. The pancreatic nodule seen in Fig. 17 enlarged. Tubules of acinar cells surround the Islet of Langerhans. Mason's Trichrome stain. 100X.

Key to abbreviations used in Plave V:

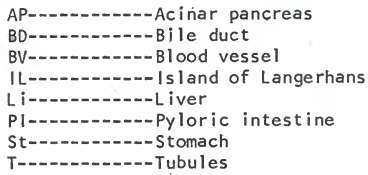


PLATE V
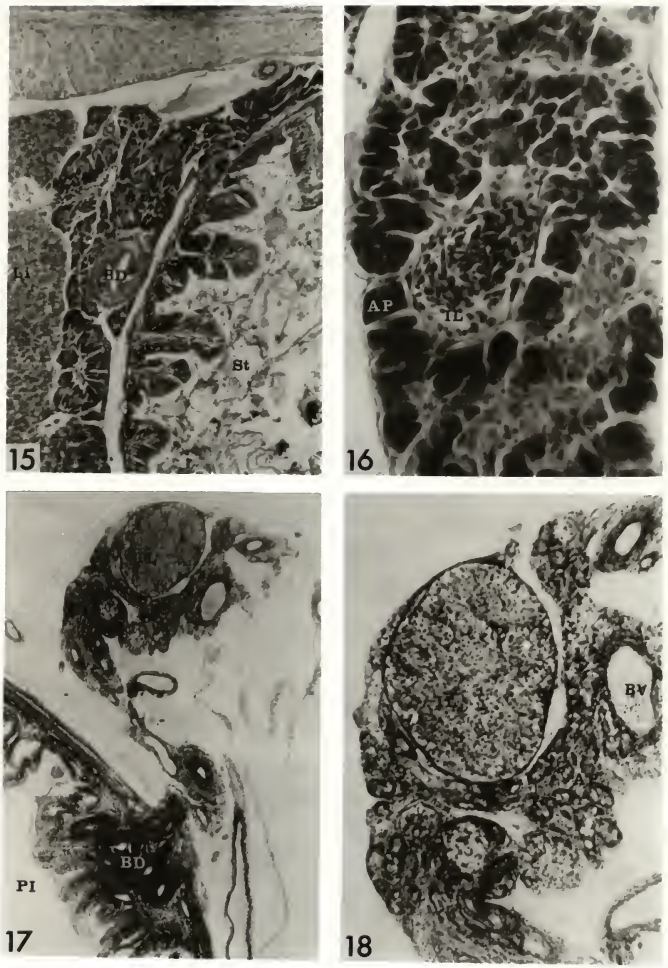
The pancreatic cells are cuboidal with round vesiculate nuclei. Secretory granules at the apical ends of the cells stain an intensive red with Mason's trichrome but do not stain distinctively with PAS. Connective tissue is interspersed between the pancreatic tubules but does not penetrate into the tubules.

Islands of Langerhans are found throughout the pancreatic tissue with some collagen fibers around them but none of the fibers penetrate into the islets (Figs. 16, 17, 18). An extensive capillary system permeates the islets with only one or two layers of pancreatic cells between capillaries in most places. The islet cells stain less intensely with Orange-G and Acid Fuchsin or with Mason's Trichrome than do the other pancreatic cells. Only one cell type is found in the islands. The cells are polygonal with round vesiculate nuclei which have a fine chromatin network and one nucleous in each nucleus (Fig. 16). The cytoplasm show no secretion granules with the stains used.

\section{DISCUSSION}

The mouth of the channel catfish is adapted for bottom-feeding by being not highly protrusible and equipped with rudimentary lips bearing barbels. The mouth of other bottom-feeders (Al-Hussaini, 1946; Girgis, 1952; Blake, 1936) is similar to that of the channel catfish. The pads of teeth immediately internal to the lips function, with the jaws, in mincing large pieces of food, a feature most of ten associated with predaceous fishes. Gill rakers are moderately developed in the 
channel catfish unlike the highly developed rakers in plankton-feeders (Al-Hussaini, 1947; Blake, 1936). The pharyngeal tooth pads in the channel catfish function as a grinding apparatus, comparable to those of the bottom-feeders which Al-Hussaini (1946) described as a mill mechanism.

The esophagus is little more than a short constriction between the posterior pharynx and the stomach, distinguished from the pharynx by the presence of a circular muscle layer and by the increase in mucosal foldings. The mucosal folds make possible great distention, thus accommodating large food items.

The presence of stratified squamous epithelium in the esophagus of the channel catfish is a distinct variation from the condition reported in some other fishes (Blake, 1930; Green, 1930; Al-Hussaini, 1946 and 1947) where the epithelium is of columnar or stratified columnar cells. I considered the epithelium to be stratified squamous because the surface layer is of the squamous type. There are areas in which the subsurface cells appeared to be columnar; in many other areas the cells were so distorted by the presence of numerous goblet cells that their shape could not be accurately determined. Blake (1930) considered the columnar cells to be undifferentiated goblet cells, which apparently is the case in the channel catfish. Columnar cells were not distinguishable in areas where goblet cells were numerous. As in other fishes, there are muscle fibers in the esophageal submucosa of the channel catfish. Blake (1936) considered these muscles in the sea robin to connect with 
the tunica muscularis, while in the sea bass, he found no connection between the two layers. He agreed with other authors (Girgis, 1952; Mohsin, 1962; and Bishop and Odense, 1966) that these fibers were the longitudinal muscle layer of the muscularis externa of the esophagus. In the submucosa of the channel catfish the muscle fibers were interwoven with the fibers of the muscularis mucosa of the stomach and, therefore, are considered a muscularis mucosa of the esophagus. Because these are the only longitudinal muscle fibers in the esophagus, the esophageal muscularis externa of the catfish is composed only of a layer of circular muscle.

The channel catfish has a true stomach which is divisible grossly into cardiac, fundic, and pyloric regions; pyloric caeca are absent. Blake (1930) described the stomach of the sea bass as divisible into a cardiac region with heavy mucosal folds and a pyloric region devoid of folds. A similar pattern is found in the channel catfish; however, the fundic region is distinguished by its pouch-like shape and by the transition from the heavy folds of the cardiac region to the lower foldings characteristic of the pyloric region. Blake (1930) found the stomach of the sea bass to have a posterior cardiac region with gastric glands and a pyloric region without glands. The stomach of the channel catfish can be divided histologically into a region containing numerous gastric glands and a region devoid of these glands. It should be emphasized that the boundaries of the morphologically distinct cardiac and fundic regions are not distinct histologically, but that both of these regions are characterized by the presence of gastric glands. Thus, 
histologically the cardiac and fundic regions are no more than a subdivision of the glandular portion of the stomach. The ability to define a fundic region in the channel catfish will be useful in describing and locating specific areas in the glandular portion of the stomach.

The secretory action of the columnar epithelium of the stomach of the channel catfish is indicated by the intense PAS reaction it shows. Mohsin (1962) reported that Starling found such gastric cells secreted both mucous and acid. The gastric glands of the channel catfish are composed of one cell type. Blake (1930) found the gastric glands of the sea bass were composed of one cell type and determined that the secretion of these glands contained pepsin only. The muscle layers of the stomach of the channel catfish are comparable to those found in other fishes which possess a true stomach.

The intestine is uniform in diameter throughout its length and exhibits no signs of the intestinal bulb or swelling common to the stomachless fish. The intestinal tract of $f$ ishes is reported to lack specialization. While in the channel catfish, the central part of the intestine is coiled, the macroscopic appearance of the intestinal mucosa is uniform throughout the entire length. The histological variation in the intestinal mucosa is characterized by an increase in number of goblet cells in the caudal regions and by the presence of shallow glands in the anterior portions of the tract. A survey of the literature indicates there are differences of opinion as to whether there are true multicellular glands in the intestine of some fishes. In those 
instances in which the presence of multicellular glands is accepted there are disagreements as to the type of glandular structure. Weisel (1962) was unable to find multicellular glands in the intestine of the longnose sucker. Blake (1936) noted in the sea robin that the orientation of the mucosa at sectioning could cause the elongated mucosal folds to appear as tubular glands. In transverse section the folds appeared simple tubular glands, but if cut at an angle they appeared as compound tubular glands. Because the cells in these structures did not differ in type from the cells which comprised the epithelial lining of the intestine, he did not consider the structures to be true glands. The structures identified as glands in the channel catfish were tubular glands because at the point where they open into foveolae they are true tubular structures as determined from serial sections or transverse sections of comparable tubules.

The lengths of the anatomical divisions of the digestive tract of several fish of varying sizes and weights are recorded in Table I. Individual variation in intestinal length is to be expected due both to the amount of food consumed and to the amount of undigested food present when fish were killed. Thus, the variation in lengths recorded in Table I are considered to be representative of the range of intestinal length possible in this species. A comparison of the lengths of the gut to the length of the $\mathrm{fish}$ is presented in Table 11 , and Table 111 is a comparison of the lengths of the divisions of the gut with the overall length of the gut.

Each pancreatic nodule is composed of minute nodules of acinar and endocrine cells. The acinar or exocrine cells are arranged into tubular 
TABLE

NUMBER, LENGTH AND WEIGHT OF FISH AND LENGTH

OF VARIOUS PORTIONS OF THE GUT

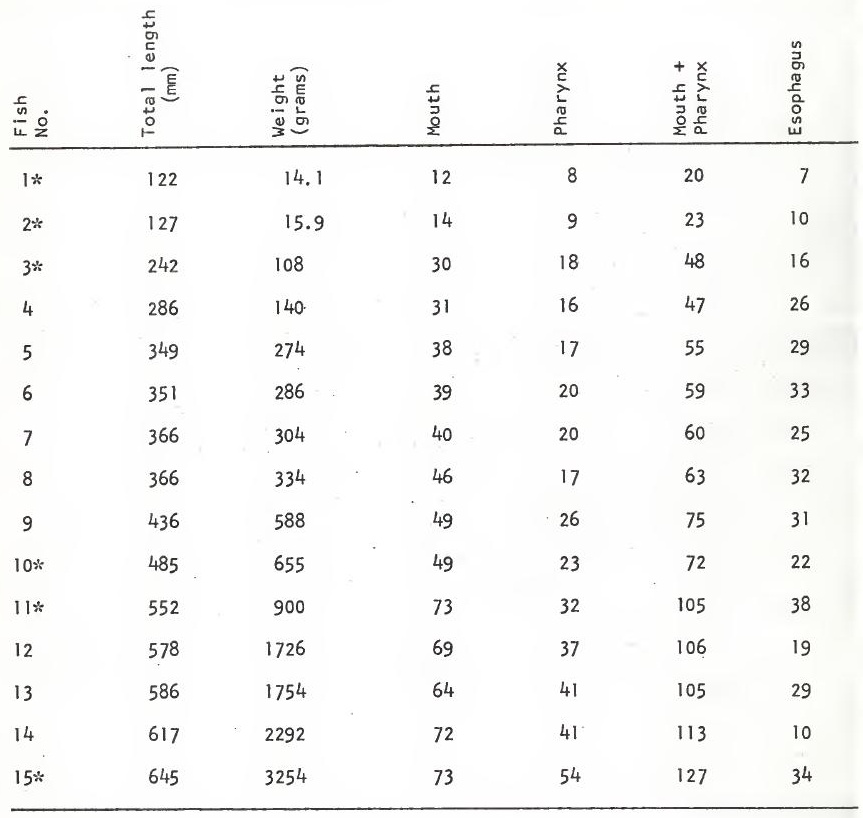

* Formalin fixative--all others fresh. 


\begin{tabular}{|c|c|c|c|c|c|c|c|}
\hline \multicolumn{3}{|c|}{ Stomach } & \multicolumn{4}{|c|}{ Intestine } & \multirow{2}{*}{ 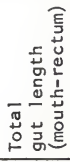 } \\
\hline $\begin{array}{l}0 \\
0 \\
0 \\
0 \\
0 \\
0\end{array}$ & $\frac{u}{\frac{0}{5}}$ & 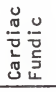 & $\frac{u}{\frac{0}{0}}$ & $\frac{0}{\frac{0}{7}}$ & $\begin{array}{l}\bar{\pi} \\
\stackrel{0}{0} \\
\stackrel{0}{0}\end{array}$ & 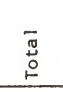 & \\
\hline 15 & 9 & 24 & 22 & 41 & 9 & 72 & 123 \\
\hline 16 & 11 & 27 & 31 & 52 & 11 & 94 & 154 \\
\hline 15 & 14 & 29 & 42 & 173 & 25 & 240 & 333 \\
\hline 19 & 27 & 46 & 44 & 245 & 22 & 311 & 430 \\
\hline 28 & 16 & 44 & 49 & 106 & 62 & 217 & 345 \\
\hline 13 & 19 & 32 & 41 & 404 & 34 & 479 & 603 \\
\hline 21 & 31 & 52 & 48 & 370 & 54 & 472 & 609 \\
\hline 25 & 41 & 66 & 82 & 131 & 37 & 250 & 411 \\
\hline 34 & 40 & 74 & 46 & 491 & 36 & 573 & 753 \\
\hline 33 & 32 & 65 & 58 & 245 & 46 & 349 & 508 \\
\hline 49 & 55 & 104 & 149 & 1016 & 93 & 1258 & 1505 \\
\hline 99 & 69 & 168 & 123 & 712 & 59 & 894 & 1187 \\
\hline 58 & 49 & 107 & 135 & 700 & 100 & 935 & 1176 \\
\hline 89 & 52 & 141 & 123 & 550 & 57 & 730 & 994 \\
\hline 115 & 65 & 180 & 147 & 1468 & 88 & 1703 & 2044 \\
\hline
\end{tabular}


TABLE $\mid$

LENGTH OF GUT DIVIDED BY FISH LENGTH

(IN PERCENTAGES)

\begin{tabular}{|c|c|c|c|c|c|}
\hline $\begin{array}{l}\text { Fish } \\
\text { No. }\end{array}$ & $\begin{array}{l}\text { Mouth + } \\
\text { Pharynx }\end{array}$ & Esophagus & $\begin{array}{l}\text { Stomach } \\
\text { (total) }\end{array}$ & $\begin{array}{l}\text { Intest ine } \\
\text { (total) }\end{array}$ & Mouth-Rectum \\
\hline $1 *$ & 16 & 6 & 20 & 59 & 101 \\
\hline $2 *$ & 18 & 8 & 21 & 74 & 121 \\
\hline $3 *$ & 20 & 7 & 12 & 99 & 138 \\
\hline 4 & 16 & 9 & 16 & 109 & 150 \\
\hline 5 & 16 & 8 & 13 & 62 & 99 \\
\hline 6 & 17 & 9 & 9 & 137 & 172 \\
\hline 7 & 16 & 7 & 14 & 129 & 166 \\
\hline 8 & 17 & 9 & 18 & 68 & 112 \\
\hline 9 & 17 & 7 & 17 & 131 & 173 \\
\hline $10 *$ & 15 & 5 & 13 & 72 & 105 \\
\hline $11 *$ & 19 & 7 & 19 & 228 & 273 \\
\hline 12 & 18 & 3 & 29 & 155 & 205 \\
\hline 13 & 18 & 5 & 18 & 160 & 201 \\
\hline 14 & 18 & 2 & 23 & 118 & 161 \\
\hline $15 *$ & 20 & 5 & 28 & 264 & 317 \\
\hline
\end{tabular}

* Formalin fixative--all others fresh. 
TABLE \|\|

LENGTH OF GUT DIVIDED BY TOTAL GUT LENGTH
(IN PERCENTAGES)

\begin{tabular}{lcccc}
\hline $\begin{array}{l}\text { Fish } \\
\text { No. }\end{array}$ & $\begin{array}{l}\text { Mouth }+ \\
\text { Pharynx }\end{array}$ & Esophagus & $\begin{array}{c}\text { Stomach } \\
\text { (total) }\end{array}$ & $\begin{array}{c}\text { Intestine } \\
\text { (total) }\end{array}$ \\
\hline $1 *$ & 16 & 6 & 20 & 58 \\
$2 *$ & 15 & 7 & 17 & 61 \\
$3 *$ & 14 & 5 & 9 & 72 \\
4 & 11 & 6 & 11 & 72 \\
5 & 16 & 8 & 13 & 63 \\
6 & 10 & 6 & 5 & 79 \\
7 & 10 & 4 & 8 & 78 \\
8 & 15 & 8 & 16 & 61 \\
9 & 10 & 4 & 10 & 76 \\
$10 *$ & 14 & 4 & 13 & 69 \\
$11 *$ & 7 & 3 & 7 & 83 \\
12 & 9 & 2 & 14 & 75 \\
13 & 9 & 3 & 9 & 79 \\
14 & 11 & 1 & 9 & 74 \\
$15 *$ & 6 & 2 & 93 \\
\hline & 9 & & 9 & 83 \\
\hline
\end{tabular}

* Formalin fixative--all others fresh. 
extensions which connect with the next nodule such that all of the nodules, which grossly appear to be isolated, are in fact connected to other nodules. The tubule system formed by the exocrine cells was the only duct system present and was difficult to recognize in many instances since it is extremely fine and thus of ten collapsed on a prepared slide. The literature is difficult to interpret since many of the authors (McCormick, 1924; Grosso, 1950) referred to the diffuse nodules of pancreatic tissue as "islets". It is often impossible to determine whether they are referring to these as "islets" because of their physical location or because they are composed of Island of Langerhans cells. For this reason 1 prefer to call the clumps of pancreatic tissue "nodules" since they contain both types of cells. 


\section{ACKNOWLEDGMENTS}

I would like to express my sincere gratitude and appreciation to Dr. 0. W. Tiemeier, Dr. H. T. Gier, and Dr. R. Klemm for their guidance and counsel throughout the course of this study and for the many valuable suggestions and constructive criticisms they offered. Their encouragement and faith in me were instrumental in the successful completion of this study. I am indebted to Dr. Tiemeier and Dr. Gier for the use of their laboratories and facilities which they offered so generously and unselfishly. I also thank my sister-in-law, Janet Harper, for her help with typing, and my wife, Kay, for her understanding throughout the course of this study.

Financial support was provided by the Agricultural Experiment Station of Kansas State University, the Kansas Forestry, Fish and Game Commission and the Bureau of Commercial Fisheries under PL88-309. I hope this study will prove to be of value to these agencies and will help them assist others interested in fish and the fisheries industries.

I also thank those that support this institution, helping in this way to provide for this study and for the educational opportunity offered to me. 


\section{LITERATURE CITED}

Al-Hussaini, A. H. 1945. The anatomy and histology of the alimentary tract of the coral feeding fish (Scarus soridus (Klunz)). Bulletin of Institut d'Egypte. 27:349.

Al-Hussaini, A. H. 1946. The anatomy and histology of the alimentary tract of the bottom-feeder, Mulloides auriflamma. Journal of Morphology. 78:121.

Al-Hussaini, A. H. 1947. The feeding habits and the morphology of the alimentary tract of some teleosts. Publications of the Marine Biology Station Ghardaga (Red Sea). 5.

Al-Hussaini, A. H. 1949. On the functional morphology of the alimentary tract of some $\mathrm{fish}$ in relation to differences in their feeding habits: anatomy and histology. Quarterly Journal of Microscopic Science. 90:109.

Barrington, E. J. W. Physiology of Fishes. Vol. 1, 1957, pp. 109-161.

Bishop, C. and P. H. Odense. 1966. Morphology of the digestive tract of the cod, Gadus morhua. Journal of Fish Research B Canada. $23(10): 1607$.

Blake, I. H. 1930. Studies on the comparative histology of the digestive tube of certain teleost fishes. I. A predaceous $\mathrm{fish}$, the sea bass (Centrpristes strictus). Journal of Morphology and Physiology. 50:39.

Blake, I. H. 1936. Studies on the comparative histology of the digestive tube of certain teleost fish. III. A bottom-feeding $\mathrm{fish}$, the sea robin (Prionotus carolinus). Journal of Morphology. $60: 77$.

Chan, Mebig Vioet. 1941. The histology of the alimentary tract of the deep water Gunare Peristedion Longispatha. University of Nebraska Studies in Science and Technique No. 1. 41.

Cross, Frank B. 1967. Handbook of fishes of Kansas. State printer, University of Kansas. 205.

Curry, Edith. 1939. The histology of the digestive tube of the carp (Cyprinus carpio communis). Journal of Morphology. 65:53.

Girgis, Sabet. 1952. On the anatomy and histology of the alimentary tract of an herbiverous bottom-feeding cyprinoid fish, Labeo horie (Cuvier). Journal of Morphology. 90:317. 
Greene, C. W. 1913. Anatomy and histology of the alimentary tract of the king salmon. Bull. U. S. Fish. 32:73.

Grosse, L. L. 1950. The effect of alloxan on the pancreas, liver and kidney of the teleost, Lebistes reticulatus, with a note on the normal pancreas. Zoologica. 35:169.

Jacobsen, Elly M. 1939. Anatomy and histology of the digestive tract of a deep sea fish Coelorhynchus carminatus. 39-40.

Lagler, K. F., J. E. Bardach, R. R. Miller. 1962. Ichthyology: the study of fishes. John Wiley and Sons, Inc. New York, Sydney.

Malcom, Jollie. 1962. Teleost digestive tract gross anatomy of perch and salmon. Chordate Morphology. 266.

McCormick, N. A. 1924. The distribution and structure of the islands of Langerhans in certain fresh-water and marine fishes. Trans. Roy. Canadian Inst. 15:57.

McVay, J. A. and H. W. Kaan. 1940. The digestive tract of Carassius auratus. Biol. Bul1. 78:53.

Mohsin, Mohd S. 1961. The morphology and histology of the alimentary canal of Glossogobius giurus (Ham). Can. J. Zool. 39(1961):605.

Rogick, Mary D. 1931. Studies on the comparative histology of the digestive tract of certain teleost fishes. Il. A minnow (Compostoma anomalum). J. Morph. Physiol: 52:1.

Sehgal, Prem (Miss). 1966. Anatomy and histology of the al imentary canal of Labeo calbasu (Hamilton). Res. Bull. (N.S.) of the Punjab Univ. 17 III-IV: 257.

Weisel, George F. 1962. Comparative study of the digestive tract of a sucker, Catostomus catostomus, and a predaceous minnow, Ptychocheilus oregonense. The American Midland Naturalist. 334. 
THE GROSS AND MICROANATOMY OF THE DIGESTIVE TRACT AND PANCREAS OF THE CHANNEL CATFISH, ICTALURUS PUNCTATUS

by

RONALD LESTER GAMMON

B. S., Kansas State University, 1968

B. S., Kansas State University, 1970

AN ABSTRACT OF A MASTER'S THESIS

submitted in partial fulfillment of the

requirements for the degree

MASTER OF SCIENCE

Division of Biology

KANSAS STATE UNIVERSITY

Manhattan, Kansas 
This study was made to determine relations of structure and function of the digestive system of the channel catfish, Ictalurus punctatus. Gross anatomy of the digestive tract and pancreas was established by dissection and measurements of 45 animals from 5 to $650 \mathrm{~mm}$ long. Microanatomy was determined from Bouin's fixed, paraffin sectioned tissues. from 30 animals. The sections were stained with PAS-hematoxylin, Mason's trichrome, Harris' hematoxylin, and acid fuchsin orange G.

The length of the gut was equal to the total length of the small $\mathrm{fish}$, and three times the length of $\mathrm{fish}$ over $500 \mathrm{~mm}$ long by increase in the intestine. The gut was shorter in winter than in summer, reflecting the higher rate of summer feeding.

The digestive tract comprises mouth, pharynx, esophagus, stomach, and intestine.

The oral cavity of the channel catfish is dorsoventrally flattened with pads of cardiform teeth immediately internal to the lips. Gill rakers are moderately developed and tooth pads on dorsal and ventral walls of the pharynx form a grinding apparatus. The wall of buccal and pharyngeal cavities comprises submucosa and a mucosa with stratified squamous epithelium which contains taste buds and numerous goblet cells. The esophagus is short with the mucosa complexly folded. The primary folds are longitudinal and more numerous than in the stomach. The wall of the esophagus is mucosa, submucosa, muscularis externa and, in the posterior portion, a serosa. The esophageal epithelium is stratified squamous with many goblet cells. The submucosa includes a discontinuous 
layer of longitudinal fibers of muscularis mucosa. The muscularis externa is entirely a circular layer of striated muscle fibers.

The stomach is divided into a cardiac region, bag-like fundic region with heavy mucosal folds, and a pyloric region with low mucosal folds. The cardiac and fundic regions together are about two thirds of the entire stomach. The columnar epithelium is continuous with numerous gastric glands within the mucosa of the cardiac and fundic regions but not in the pyloric region. A pyloric valve separates the stomach from the intestine. The muscularis externa is composed of inner circular, outer longitudinal and intermediate oblique layers. The intestine varies little throughout its length either grossly or microscopically, but may be divided into pyloric, middle, and rectal regions for purposes of identification. The intestinal wall is composed of mucosa, submucosa, muscularis externa and serosa. The mucosal epithelium is simple columnar to pseudostratified columnar cells, with goblet cells being most numerous in the posterior regions. In the pyloric and middle regions, simple multicellular glands empty into the mucosal crypts through short tubular ducts. The muscularis externa is smooth muscle fibers arranged as an inner circular layer and an outer longitudinal layer. The connective tissue layer of the serosal coat increases in the caudal regions. Muscularis mucosa is lacking posterior to the pyloric valve.

Pancreatic nodules, containing both exocrine and endocrine cells occur as small whitish nodules in the mesenteries and are most numerous along the pyloric portion. The acinar cells form tubules which join the 
bile duct. No other pancreatic duct system was found. The endocrine cells form islets of Langerhans that are extensively vascularized. A few small nodules containing both endocrine and exocrine cells occur as far posteriorly as the rectal segment of the intestine.

The goblet cells of the esophagus and the gland cells of the stomach and intestine contained secretion droplets at all times of the year, without relation to the amount of food eaten, indicating that the presence of food was involved in release of secretion rather than production. 